\title{
Views of Medical Educators and Intern Doctors on the Existing MBBS Curriculum
}

\author{
Abu Syed Md. Mosaddek', Waheeda Nargis ${ }^{2}$,Borhan Uddin Ahamed ${ }^{3}$, Md. Zakirul Islam ${ }^{5}$, Habib S. Chaudhury ${ }^{6}$, Most. \\ Fahmida Begum ${ }^{7}$ Md. Faizur Rahman ${ }^{8}$, Rumana Alim ${ }^{9}$
}

\begin{abstract}
This study was carried out to get an idea about the views of medical educators and intern doctors regarding the current undergraduate medical curriculum. A partially descriptive open ended questionnaire was distributed among teachers of all three phases and intern doctors in undergraduate curriculum in different public and private medical colleges in Bangladesh and was returned by 120 teachers and 663 intern doctors. Qualitative analysis of data was done. Among teachers $70 \%$ agreed to need for changes, $68.4 \%$ were in favor of present internship training system and $85 \%$ were against 'carry on' system. But $94 \%$ and $51 \%$ of intern doctors were in favor of need changes of curriculum and present internship training respectively. $91 \%$ were against 'carry on' system.
\end{abstract}

Key Words: Medical educators, Curriculum, Intern doctors.

\section{Introduction}

The word curriculum derives from the Latin currere meaning 'to run'. Curriculum refers to a series of planned activities that are intended to bring about specific learning outcomes. It is the blue print that entails the goal of any educational activities and endeavors to achieve the goal ${ }^{1}$. Curriculum development is a comprehensive term that includes the processes of curriculum design, implementation and evaluation ${ }^{2}$. It is also specialized task which requires systematic thinking about the objectives to be achieved, learning experiences to be provided, evaluation of changes brought out by the curricular activities. Today the definition is much wider and includes all the planned learning experiences of a school or educational institution'.

In recent years, medical education in developed and developing countries has undergone profound changes. To cope with these changes, medical schools around the world have attempted to make their curricula more meaningful

\footnotetext{
${ }^{1}$ Department of Pharmacology, Uttara Adhunik Medical College, Uttara, Dhaka;

${ }^{2}$ Department of Biochemistry, Uttara Adhunik Medical College, Uttara, Dhaka;

${ }^{3}$ Department of Forensic Medicine, Dhaka Community Medical College, Moghbazar, Dhaka;

${ }^{4}$ Department of Pharmacology, Eastern Medical College, Comilla; ${ }^{5}$ Department of Biochemistry, International Medical College, Gazipur;

${ }^{6}$ Department of Microbiology, Uttara Adhunik Medical College, Uttara, Dhaka;

${ }^{7}$ Department of Pharmacology, Eastern Medical College, Comilla.

${ }^{8}$ Department of Microbiology, Medical College for women and hospital, Uttara, Dhaka.
}

Address of correspondence: ASMM

E-mail: Drmosaddek@yahoo.ca and relevant to the needs of the time and to produce doctors oriented to the real needs of the community.

Medical education in Bangladesh has also experienced many changes and challenges. In Bangladesh a set up for undergraduate medical education was continued from the pre-liberation period up to 1988 . Then a great change was brought about in curriculum in 1988 by making it more community oriented ${ }^{4}$. Although, it was a combined product of reorientation of medical education and community oriented medical education but a thoroughly revised new curriculum for undergraduate MBBS course was implemented in 2002 in Bangladesh aiming at qualitative improvement in medical education ${ }^{5}$. This new problem oriented curriculum for undergraduate medical education was introduced following the recommendations of medical educationists and it was approved by Bangladesh Medical and Dental Council ${ }^{6}$.

It divided the long 5 years course into three parts by first, second and third professional examinations. The students have to face a lot of formative examinations in each discipline. Item examinations (covering shortest content area; e.g. 1-3 topics), card examinations (covering several items; e.g. single body area or system) and term examinations (covering several items and card; e.g. twothree body areas or systems) are three types of formative assessment are held in the medical colleges to enhance intern doctor's learning and academic activities .

The MBBS students are being taught by lectures, tutorials, practical demonstrations and bedside clinical teachings. Modern teaching aid like OHP, multimedia, models were facilitating the classes of MBBS course. A good number of teachers is also trained on modern teaching and assessment methods 5 .

Bangladesh Journal of Medical Education 2012;3(1):8-11. (C) 2012 Mosaddek et al., publisher and licensee Association for Medical Education. This is an Open Access article which permits unrestricted non-commercial use, provided the original work is properly cited. 
More than 5 years have been passed by this time after introducing the MBBS curriculum 2002. There might be some areas, which should incorporate the changing needs of people of the country. It is the best time to revise the existing curriculum to find out its strength and weakness and thereby improving it. Only few studies have yet been reported on how the teachers and students are coping with it. Keeping those in mind, this study was designed to get the views of senior teachers and intern doctors regarding undergraduate medical curriculum of Bangladesh to find out whether there is any need for change in this undergraduate medical curriculum.

\section{Methodology}

It is a cross-sectional, questionnaire based study. The study was conducted among the senior medical teachers (Professors and Associate Professors) and intern doctors of different government and non-government medical colleges in Bangladesh. The teachers were selected purposively. The questionnaire included questions on different aspects of implementation of undergraduate curriculum in different medical colleges. Data was collected and qualitative analysis was done.

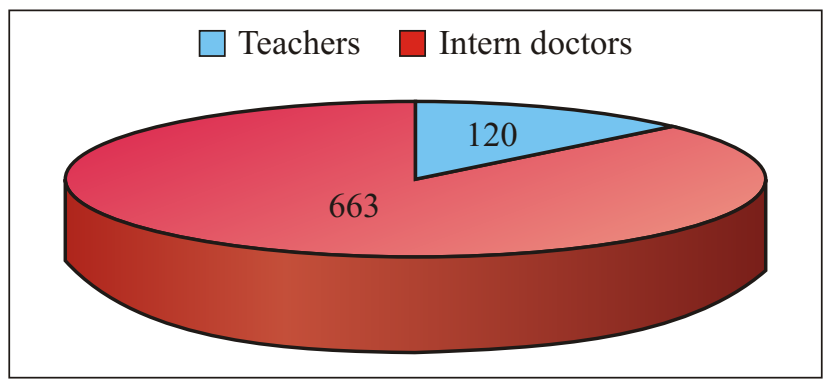

Figure-1: Distribution of total respondents.

\section{Results}

Total participants were 783 in which 120 were senior teachers and 663 were intern doctors (figure-1). Respondents from public medical colleges in both teachers and intern doctors were greater than that of private medical colleges (figure-2).

Majority of participants agreed with present format of admission test and internship training. But most of them were not satisfied with different aspects of MBBS curriculum, 2002.

Majority of respondents were not facing any difficulty regarding course content, time duration and evaluation system. Regarding 'Carry on system' there was highly significant difference between the opinions from teachers and intern doctors. Most of the teachers were against it but majority of intern doctors were in favor of it. Most of the teachers and intern doctors were viewed that pre-medical education is not required.

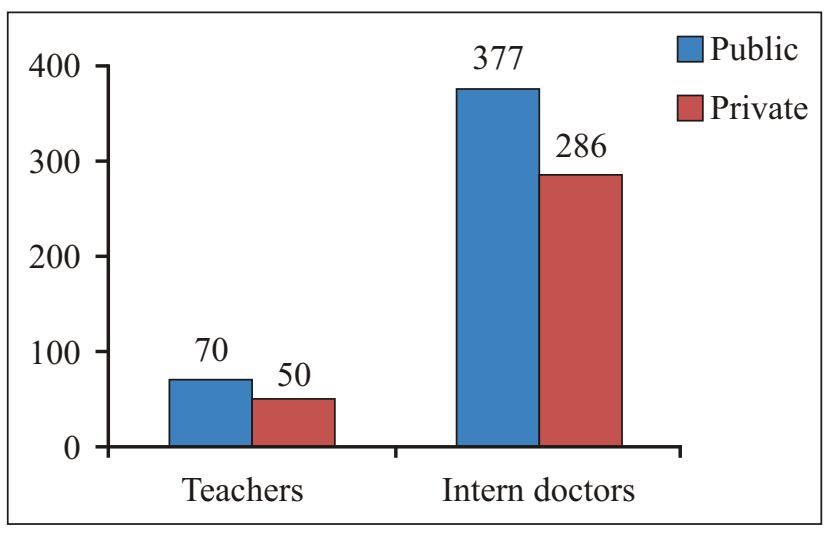

Figure-2: Categorical Distribution of study subjects.

Table-1: Respondents' views towards admission test, new curriculum, and internship training.

\begin{tabular}{lcccc}
\hline Comment & Respondent & Admission Test & New MBBS Curriculum & Internship Training \\
\hline Satisfied with current & Teachers & $90(75 \%)$ & $38(31.7 \%)$ & $82(68.3 \%)$ \\
format & Intern doctors & $366(55.2 \%)$ & $39(5.9 \%)$ & $339(51.1 \%)$ \\
& p-value & $>0.05$ & $<0.001 *$ & $>0.05$ \\
Need change & Teachers & $30(25 \%)$ & $82(68.3 \%)$ & $38(31.7 \%)$ \\
& Intern doctors & $297(44.8 \%)$ & $624(94.1 \%)$ & $324(48.9 \%)$ \\
& p-value & $<0.05$ & $<0.05$ & $>0.05$ \\
\hline
\end{tabular}

* The level of significance at $<0.001$.

Bangladesh Journal of Medical Education 2012;3(1):8-11. 
Table-2: Respondents' view about difficulty in different aspects of curriculum and requirement of Pre-medical education.

\begin{tabular}{lccccc}
\hline \multirow{2}{*}{ Components } & \multicolumn{2}{c}{ Teachers } & \multicolumn{2}{c}{ Intern doctors } & \multirow{2}{*}{ P -value } \\
\cline { 2 - 5 } & Yes & No & Yes & No & \\
\hline Content & $24(20 \%)$ & $96(80 \%)$ & $27(4.1 \%)$ & $636(95.9 \%)$ & 0.001 \\
Time duration & $48(40 \%)$ & $72(60 \%)$ & $258(38.9 \%)$ & $405(61.1 \%)$ & 0.902 \\
Evaluation & $24(20 \%)$ & $96(80 \%)$ & $102(15.4 \%)$ & $561(84.6 \%)$ & 0.439 \\
Carry on system* & $102(85 \%)$ & $18(15 \%)$ & $60(9 \%)$ & $603(91 \%)$ & $<0.001$ \\
$\begin{array}{l}\text { Requirement of Pre- } \\
\text { medical education }\end{array}$ & $26(21.7 \%)$ & $94(78.3 \%)$ & $207(31.2 \%)$ & $456(68.8 \%)$ & 0.191 \\
\hline
\end{tabular}

* The level of significance at $<0.001$.

Table-3: Respondents' comment on different aspects of current evaluation system.

\begin{tabular}{lccccc}
\hline \multirow{2}{*}{ Different aspects } & \multicolumn{3}{c}{ Teachers } & \multicolumn{2}{c}{ Intern doctors } \\
\cline { 2 - 5 } & Satisfactory & Unsatisfactory & Satisfactory & Unsatisfactory & \\
\hline Written & $96(80 \%)$ & $24(20 \%)$ & $648(97.7 \%)$ & $15(2.3 \%)$ & 0.184 \\
Oral & $66(55 \%)$ & $54(45 \%)$ & $579(87.3 \%)$ & $84(12.7 \%)$ & $0.006^{*}$ \\
Practical & $90(75 \%)$ & $30(25 \%)$ & $612(92.3 \%)$ & $51(7.7 \%)$ & 0.181 \\
\hline
\end{tabular}

*The level of significance at $<0.01$.

Majority of respondents were satisfied with different aspects of current evaluation system.

Table-4: Respondents' view regarding difficulty in respective phases.

\begin{tabular}{cccccc}
\hline \multirow{2}{*}{ Phases } & \multicolumn{4}{c}{ Teachers } & \multicolumn{2}{c}{ Intern doctors } & P -value \\
\cline { 2 - 5 } & Yes & No & Yes & No & 0.536 \\
Phase - I & $18(15 \%)$ & $102(85 \%)$ & $78(11.8 \%)$ & $588(88.2 \%)$ & 0.227 \\
Phase - II & $48(40 \%)$ & $72(60 \%)$ & $198(29.9 \%)$ & $465(70.1 \%)$ & 0.053 \\
Phase - III & $24(20 \%)$ & $96(80 \%)$ & $63(9.5 \%)$ & $600(90.5 \%)$ & \\
\hline
\end{tabular}

There was no significant difference $(\mathrm{p}>0.05)$ of opinion regarding phase specific evaluation. Most of the respondents (both teachers and intern doctors) were satisfied with present format of phase-I\&III. Majority of respondents from phase-II were not facing any difficulty but it was lower than that of phase-I\&III.

\section{Discussion}

Curriculum development is a continuous process. Majority of medical education programs at present have become community oriented student centered with active learning of learners rather than a more didactic, teacher-led approach. Most medical schools, especially in South-East Asia, currently are experiencing difficulties in providing the right quality and quantity of educational experiences as the curricula have failed to respond to the needs of the community and country ${ }^{3,7}$.

Present undergraduate medical curriculum was implemented in 2002 in Bangladesh. Evaluation of curriculum by senior teachers and students is necessary to make it more community oriented, student centered. This study revealed that majority of both senior teachers $(68 \%)$ and intern doctors (94\%) were not supporting this curriculum in different aspects ${ }^{6,8-11}$ but most of the studies done previously reported in favor of present MBBS curriculum. This study also included evaluation of existing admission test, and internship training as well as introducing premedical education.

Bangladesh Journal of Medical Education 2012;3(1):8-11. 
Regarding these points participants valued with interning proposal likeauthenticating entrance exam with increased number of questions and time, rearrangement of seat plans, bringing total system under proper supervision of a transparent committee, proper utilization of internee period with adequate technical support, proper guidance of senior teachers, community oriented training, implementation of rational prescribing practices and introduction of pharmacology at the initial period. Majority of participants from both categories discouraged premedical education. Regarding 'carry on system' senior teachers and intern doctors were on different poles. Major portion (91\%) of intern doctors were in favor of it but most of the teachers (85\%) did not support it.

Opinion of majority senior teachers and intern doctors were same about present course content, duration and evaluation system and they were satisfied with present format as in studies done earlier ${ }^{9,10}$. Rest of the participants from both categories were in favor of reduction of course content, extension of duration of course, modification of teaching learning method with more emphasized on practical examination ${ }^{8}$.

Majority of teachers as well as intern doctors were satisfied with each component of the current evaluation system ${ }^{8}$. Both teachers and intern doctors who were not in favor of present format shared some common view like increasing MCQ of written examination, making topic based and standard oral questions and providing them from a central examination committee and changing examination schedules and improving practical examination with standard laboratories of all concerned departments ${ }^{11}$.

In specific phase related analysis suggestion from participants were exclusion of community medicine from phase-I, scheduling each professional examination more frequently, expending duration before $1^{\text {st }}$ professional examination, introducing total of four professional examinations, splitting phase-II contents, better coordination of lecture and clinical classes along with timely in-course assessments converting theoretical knowledge into practical skills ${ }^{10,11}$.

\section{Conclusion}

Health care service cannot be improved unless the educational process of the medical education that produces the doctors and other health personnel are improved. The areas of changes suggested include entrance examinations, content in different discipline, time duration, evaluation system, phase rearrangement. The physicians and students today are more concerned about the existing undergraduate curriculum. So evaluation of curriculum by students and teachers may be further analyzed and taken under consideration to upgrade the curriculum

\section{References}

1. Prideaux D. Clinical review: $A B C$ of learning and teaching in medicine curriculum design, B M J 2003; 326: 268-70.

2. Wong AK. Curriculum development in anesthesia: basic theoretical principles. Canadian Journal of Anesthesia 2006 (53) 950-60.

3. Majumder MAA, D'Souza U, Rahman S. Trends in Medical Education: challenges and directions for needbased reforms of medical training in south-east Asia. Indian J Med Sci. 2004; 58:369380.

4. Karim A, Haque M. Assessment system in Pharmacology - Does it reflect educational objectives and community health needs? Bangladesh J Physiol Pharmacol. 1996; 12(2): 65-67.

5. Curriculum for under-graduate medical education of Bangladesh, 2002. Centre for Medical Education, Dhaka.

6. Ali T, Begum N, Begum AA, Shamim KM, Ferdousi S, Bennoor KS. Summative Assessment (Written) in Undergraduate Physiology Curriculum in Bangladesh: Reflection of Educational Objective. J Bangladesh Soc Physiol. 2008; 3:61-65.

7. Fraustino IR. What Medical Office Assistants do? A brief history of Medicine. Introduction to Medical office Assisting. ICS intangibles holding company, 1994; 1:27-28.

8. Talukder MHK, Hossain MZ, Hanif MA, Akther N, Perveen IA. Reviewing and Updating of MBBS Curriculum 2002: Intern Doctors' Views. Bangladesh Journal of Anatomy January 2011; 9(1):35-40.

9. Alam KK, Nargis T, Khan TF, Kasem MA, Faruque M. Need Assessment for Undergraduate Medical Curriculum of Bangladesh Through Exploring The Views of Government Primary Health Care Doctors. Bangladesh J. Anat. 2009; 7(2): 87-93.

10. R Nazneen, HK Talukder, MZ Hossain. Student's Opinion towards the Assessment System of Revised Undergraduate Medical Curriculum An Experience in A Private Medical College. J Bangladesh Coll Phys Surg 2010;28: 151-156.

11. Tyagi A. Ahuja, S, Bhattacharya A. Undergraduate medical students assessment of teaching curriculum A cross sectional study. Indian Journal of Anaesthesia, 2002; 46(3): 186-188.

Bangladesh Journal of Medical Education 2012;3(1):8-11. 